Pons \& Pausas (2012) - 1

\title{
The coexistence of acorns with different maturation patterns explains acorn production variability in Cork oak
}

\author{
Josep Pons (1) and Juli G. Pausas (2)* \\ (1) CEAM-UMH, Charles R. Darwin 14, Parc Tecnològic, 46980 Paterna, Valencia, SPAIN \\ (2) CIDE-CSIC, Campus IVIA, Crta de Nàquera km 4.5, 46113 Montcada, Valencia, SPAIN. Tel: \\ +349612205 40. Fax: +34 9612709 67. Email: juli.g.pausas@uv.es \\ * Corresponding author
}

Author Contributions: JGP conceived the idea. JP performed most of the sampling. JP and JGP analysed the data and wrote the manuscript.

\begin{abstract}
In dry areas such as Mediterranean ecosystems, fluctuations in seed production are typically explained by resource (water) availability. However, acorn production in Cork oak (Quercus suber) populations shows a very low relation to weather. Because Cork oak trees produce acorns with different maturation patterns (annual and biennial), we hypothesize that acorn production in coexisting individuals with a different dominant acorn maturation type should respond differently to climatic factors, and that disaggregating the trees according to their acorn-maturation pattern should provide a more proximal relation to weather factors. We assessed acorn production variability in fragmented Cork oak populations of the eastern Iberian Peninsula, by counting the total number of acorns in 155 trees during an eight year period. An initial assessment of acorn production variability in relation to weather parameters yielded very low explained variance (7\%). However, after grouping the trees according to their dominant acorn maturation pattern, weather parameters accounted for $44 \%$ of the variability in acorn crops: trees with annual acorns exhibited mast fruiting in years with reduced spring frost and shorter summer droughts, while trees with biennial acorns showed an opposite pattern. That is, conditions that negatively affect annual production could be beneficial for biennial production (and vice-versa). The results highlight the importance of the resource-maching hypothesis for explaining acorn production in Quercus suber, and suggest that different seed maturation types within a population may allow the species to deal with highly variable weather conditions. The results also emphasise the importance of understanding acorn maturation patterns for interpreting masting cycles.
\end{abstract}

Keywords: Quercus suber, evergreen oaks, Mediterranean woodlands, hypothesis, masting. 


\section{Introduction}

Understanding variability in seed production is a central question in ecology because it is a key component determining offspring success in plants (Venable and Brown 1988). Variability in seed production not only provides valuable insights on the potential regeneration capacity of plant populations, but as it is linked to changes in wildlife populations (Wolff 1996, Boutin et al. 2006), it is also a key ecological step in many food webs. This is especially important in oaks because they are considered typical foundation species (Ellison et al. 2005) dominating many landscapes worldwide (Rodà et al. 1999, McShea and Healy 2002, Logan 2005, Aronson et al. 2009). Indeed, acorns are crucial in many food webs, and wildlife population changes often track fluctuations in acorn production (Wolff 1996, Ostfeld et al. 1996, McShea and Healy 2002, Schmidt and Ostfeld 2003, Boutin et al. 2006, Clotfelter et al. 2007). Consequently, considerable attention has been given to understanding oak regeneration processes and acorn production patterns (Koenig and Knops 2002, Kelly and Sork 2002, Liebhold et al. 2004).

Studies on acorn production in Mediterranean Europe have been concentrated in widespread oaks like the Holm oak (Quercus ilex, e.g., García-Mozo et al. 2007, Espelta et al. 2008, Pérez-Ramos et al. 2010), and little is known for other species. In this paper our specific aim is to understand acorn production patterns in small and fragmented Cork oak (Quercus suber L.) populations of the eastern Iberian Peninsula (Mediterranean Basin; Fig. 1). This Mediterranean oak is important in terms of conservation (species protected by the European Union Habitat Directive) and also for its cultural and socio-economic value (sustainable cork production; Aronson et al. 2009, Bugalho et al. 2011). Furthermore, there is increasing evidence of the conservation and biodiversity value of fragmented peripheral populations (Lesica and Allendorf 1995; Hampe and Petit 2005, Bridle \& Vines 2007), and specifically of $Q$. suber, due to the distinct genetic pools between central and peripheral populations (Jiménez et al. 1999, Magri et al. 2007). Thus, understanding the regeneration capacity and variability of these populations is crucial for inferring their evolutionary potential and their fate in a changing world.

In their review, Kelly and Sork (2002) suggested that in dry conditions (e.g., Mediterranean ecosystems), fluctuations in seed production should be better explained by water availability. There is evidence that summer drought reduces crops by abortion of immature acorns in the Mediterranean Holm oak (Quercus ilex; Espelta et al. 2008; Pérez-Ramos et al. 2010). Furthermore, Cork oak is considered a cold-sensitive species and cold reduces flower and fruit production (García-Mozo et al. 2001). Thus, we hypothesize that Cork oak acorn production would also be driven by weather factors, specifically those related to water availability and early frosts. However, while the acorn maturation pattern of most oak species is distinct and fixed, in Cork oak it is not constant across individuals of a given population (Elena-Roselló et al. 1993, Díaz-Fernández et al. 2004). That is, Cork oak can have annual acorns (which ripen the same year as they are pollinated) or biennial acorns (i.e., acorn development extends to 2 years). There is evidence that differences in maturation timing between species may explain their different annual acorn production (e.g., Koenig et al. 1991, Fearer et al. 2008), and that this may be the consequence of the interaction of environmental parameters with different phenological stages (Abrahamson and Layne 2003). That is, adverse climatic conditions may act differently on annual than on biennial acorns because when these conditions occur the different types of acorns are at a different phase in the maturation process (Cecich and Sullivan 1999). In this framework, we predict that acorn production in coexisting individuals with a different dominant acorn maturation type should respond differently to climatic factors in a similar way to the pattern shown by annual and biennial species, and, thus, disaggregating the trees according to their acorn-maturation pattern should provide a more proximal relation to weather factors. Furthermore, previous studies showed more negative temporal 
autocorrelations in the acorn production of oak species with annual crops than in those with biennial crops (Koenig et al. 2003). We predict that this patten, described among species, should also be reproduced in Cork oak (within species), in such a way that Cork oak trees with a predominant annual acorn pattern would have a more negative temporal autocorrelation than Cork oak trees with predominantly biennial acorns.

In summary, we aim to describe the acorn production of cork oak populations and to test: 1) the relative importance of weather factors (precipitation and temperature) in explaining acorn production patterns; and 2) the importance of discriminating the individual acorn maturation pattern for understanding acorn production variability at population level.

\section{Methods}

\section{Study species}

Cork oak (Quercus suber L.) is a sclerophyllous evergreen oak that occurs in non-carbonated soils in the western part of the Mediterranean Basin (Fig.1a; for climatic requirements see Montero and Cañellas 2003, Aronson et al. 2009). The main distinctive feature of this species is its thick insulating bark which evolved as a fire protection mechanism (Pausas 1997, Pausas et al. 2009) and which regrows after extraction (i.e., for cork production; Aronson et al. 2009). Q. suber produces both annual and biennial acorns; this heterogeneous acorn maturation pattern is an oddity among oaks. Annual acorns mature the same year as the flowers which produced them, while biennial acorns grow and mature in the autumn of the following year (Elena-Roselló et al. 1993, DíazFernández et al. 2004).

\section{Study areas}

This study was conducted in the Valencia region (Spain, Eastern Iberian Peninsula) where Q. suber is rare and confined to relatively small patches (Fig. 1). Specifically, in this region there are 3 main Q. suber patches, from north to south: Espadà (Castelló, lat $=39^{\circ} 52^{\prime}$, ca. 10000 ha), Calderona (València, lat $=39^{\circ} 44^{\prime}$, ca. 1000 ha) and Pinet (València, lat $=38^{\circ} 59^{\prime}$, ca. 100 ha). We selected five $3 \times 3 \mathrm{~km}$ areas (hereafter sites) distributed on the three main patches as follows: two sites in Espadà (E1, E2), two in Calderona (C1, C2) and one in Pinet (P1) (Fig. 1b; see Pons and Pausas 2006, 2008 for further details on these sites). Soils in Calderona and Espadà are mainly acidic on sandstones (Bundsanstein, which is a Triassic bedrock) with soil $\mathrm{pH}$ ranging from 4.9 to 6.4 (mean 5.7). In Pinet, $Q$. suber occurs in non-carbonated soils on dolomites, with $\mathrm{pH}$ ranging from 5.5 to 7.5 (mean: 6.5; Cretaceous bedrock, Pausas et al. 2006). Currently, the three sites are protected either as Natural Parks (Espadà and Calderona) or as a regional plant micro-reserve (Pinet). Cork extraction is still ongoing in Espadà and Calderona. The climate at these three locations is typically Mediterranean, with hot dry summers and mild winters, and an annual rainfall ranging from 500 to $800 \mathrm{~mm}$ distributed in two peaks, spring and autumn (Pérez-Cueva 1994, Millán et al. 2005). Pinet is warmer and wetter than Calderona, while Espadà shows intermediate conditions (Fig. 2, Fig. A1 in Electronic Supplementary Material, ESM). The years 2002, 2004, 2007, 2008 and 2010 had above-average precipitation. In the case of Pinet, 2009 was wetter than 2010, and three years (2004, 2008 and 2009) received nearly double the precipitation of the other sites (Fig. 2).

\section{Sampling}

We randomly selected 172 cork oak trees $\geq 20 \mathrm{~cm} \mathrm{DBH} \mathrm{(diameter} \mathrm{at} \mathrm{breast} \mathrm{height)} \mathrm{distributed} \mathrm{over}$ the five sites. Two observers using binoculars and standing on opposite sides of each tree estimated the acorn production by counting the total number of acorns in the crown. The counting was performed in September-October, i.e., immediately prior to acorn fall (October-November) when acorns were large enough to be easily detected, and during a period of 8 years (2003-2010). For 
each sampled tree we measured the $\mathrm{DBH}$, computed the basal area, and recorded the geographical coordinates (GPS). Because our aim was to understand acorn production variability, trees with very low acorn production (i.e. less than 20 acorns) during the study period, as well as trees that were sampled less than five years, were excluded from the analysis. Thus our final data set consisted of 155 trees distributed as follows: 25 (E1), 34 (E2), 45 (C1), 23 (C2), and 28 (P1).

To test the validity of our acorn production estimations, in 2003 and 2004 we selected 25 additional trees with a range of DBH similar to the studied trees. In each of these trees we first counted acorns using the methods described above, and then determined the real acorn production by means of the traditional method of climbing the tree and beating down all the acorns with a pole. We only considered mature acorns, discarding the abortions. The relation between the visual estimation and the real acorn production was highly significant $\left(\mathrm{F}_{1,23}=731, \mathrm{R}^{2}=0.97, \mathrm{p}<0.0001\right.$; Fig. A2 in ESM), allowing us to be confident about our methodology.

\section{Weather parameters}

Climatic data (Table 1) were obtained from 81 meteorological stations in the region. Monthly number of frost days and monthly precipitation were interpolated to the center of each sampled site using the spatial module of ArcView 3.3; mean monthly temperature was obtained from the weather stations near each site, after correcting for altitude. The number of frost days was considered for the $2^{\text {nd }}$ fortnight of March (FD3b), and for the spring total (March and April; FDsp). Precipitation data was computed yearly (P) as hydrological years (from September to August) and for seasons (Psp, Psu, Pau, Pwi). Potential and actual evapotranspiration (PET and AET) was computed following Thornthwaite and Mather (1957) from monthly climatic data. For AET, we used a bucket model with the soil holding capacity inferred from available soil analyses (i.e., textures) in the study area (for Pinet: Pausas et al. 2006; for Espadà: Serrasolsas et al. 2009; for Calderona: Rubio et al. 2005). Then, water deficit (WD) was computed as PET-AET, and the drought index (DI) as DI=1 AET/PET. Mean weather values and water balance variables for each site are shown in Table A1.

\section{Data analysis}

Tree production depends not only on weather and masting cycles, but also on tree size (correlation between total acorn production during the whole period and tree basal area: $r=0.50, p<0.0001)$. Thus the number of acorns / basal area $\left(\mathrm{cm}^{2}\right)$ was used for studying the variability of acorn production among years and trees. However, acorn production may also depend on microsite characteristics (such as tree density, soil depth, bedrock type, topography, etc.). Therefore, to study the relation between weather and acorn production, we first standardised the acorn production of each tree and year by subtracting the long-term mean of the tree (over the 8 years) and dividing by the standard deviation over all the years (LaMontagne and Boutin 2007).

Acorn production was first analysed for all $(n=155)$ trees. However, the acorn maturation pattern (annual vs. biennial) in $Q$. suber varies greatly (Díaz-Fernández et al. 2004), and coexisting trees may have a dominant annual or biennial pattern. Because mast years are defined as years of exceptional seed production, two consecutive masting years are highly unusual (LaMontagne and Boutin 2009). However, preliminary analysis showed that: a) 2008 and 2009 were years with high acorn production; b) the year 2008 had the lowest water deficit during the study period (2003 to 2010; Fig. 2); and c) there was a negative relation between trees producing acorns in 2008 and those producing acorns in $2009(\mathrm{r}=-0.41, \mathrm{p}<0.0001)$. Thus we considered the trees that masted in 2008 as trees with dominant annual acorns and the trees that masted in 2009 as trees with biennial acorns (hereafter A and B trees, respectively); a third type of tree ( $\mathrm{C}$ trees) was assigned to those that did not show a clear difference between these two years (i.e., masting during the two years, or in any of the two years). For each tree, masting was defined as years in which the annual standardized deviate 
of acorn production was greater than the absolute magnitude of the variation below the mean (La Montagne and Boutin 2007, 2009). There were no differences in size (basal area) among these groups of trees $\left(\mathrm{F}_{2,152}=0.58, \mathrm{p}=0.56\right)$. Thus the statistical analysis was performed for all trees, and for A and B trees separately.

Temporal variability in acorn production was evaluated using the following parameters (Herrera 1998; Koenig et al. 2003): Mean individual synchrony (heareafter Rp; Buonaccorsi et al. 2001) was calculated as the mean of all pairwise Pearson correlations between individual trees; mean individual acorn-production variability (heareafter $\mathrm{CVi}$ ) was calculated by averaging across individuals the coefficient of variation for acorn production across years for each individual; mean population acorn-production variability (heareafter $\mathrm{CVp}$ ) was calculated as the coefficient of variation across individuals of the annual means across years for each tree; and the mean (across individuals) of the temporal autocorrelation function of acorn production was calculated at 1-year time lags (heareafter ACF1i). Variability and synchrony parameters (CVi, CVp, Rp) were computed with values of acorn production expressed as number of acorns $/ \mathrm{cm}^{2}$ of basal area, while the temporal autocorrelation was computed from the standardised acorn production values. All parameters were computed for all trees together, and then for each site and for trees with different acorn production pattern (A and $\mathrm{B}$ trees).

To evaluate the role of weather factors on acorn production variability, we tested the relationship between the standardised acorn production of each year (September[x] to December[x], where $\mathrm{x}$ is the year of the acorn production) and the relevant weather factors during the 12 months previous to the acorn production (i.e., September[x-1] to August[x]; Table 1). We also considered the same variables for the previous year (i.e., September[x-2] to August[x-1]) as they could be involved in the formation of biennial acorns. The test was performed using a mixed-effects (LME) model analysis considering trees nested within site as random factors (i.e., repeated measures analysis), and the best model was selected using a stepwise procedure based on the Akaike Information Criteria (AIC); in each step, the significance was evaluated by a likelihood ration test (with a change of 1 degree of freedom).

\section{Results}

\section{Acorn production variability}

The number of acorns produced by each tree in a given year was quite variable, ranging from 0 to more than 20000 acorns per tree, but it was strongly biased towards few acorns (median= 8 acorns per tree and year; median $=28$ acorns per tree when excluding trees and years with no acorn production; left skewed distribution). In fact, during the 8-year study period, most of the acorns produced were supplied by only a few trees; for instance, about $6 \%$ of the trees produced somewhat more than $50 \%$ of the acorns, and $20 \%$ of the trees produced $80 \%$ of the acorns (i.e., acorn production followed the Pareto principle or 80-20 rule). This biased distribution is partially due to the biased distribution in tree sizes, because when we divided the number of acorns by the tree's basal area, the distribution becomes less skewed: $20 \%$ of the trees account for about $30 \%$ of the acorns $/ \mathrm{cm}^{2}$ of basal area.

The mean annual acorn production between 2003 and 2010 in Pinet and Espadà $(0.218$ and 0.217 acorns $/ \mathrm{cm}^{2}$ of basal area, respectively) doubled the production for Calderona $\left(0.090 \mathrm{acorns} / \mathrm{cm}^{2}\right.$ of basal area ). For the total of trees, maximum production was achieved in 2008 (mast year), followed by 2003, 2009 and 2010 (Fig. 3 overall). However this pattern varied among sites: while trees in Espadà (E1, E2) masted in 2008, in Calderona (C1, C2) the maximum productions was achieved in 2009 (Fig. 3). The proportion of A and B trees also varied among sites, decreasing from Pinet to 
Calderona with Espadà showing intermediate values (Table 2). This is in agreement with the gradient from optimal conditions at $\mathrm{P} 1$ to xeric conditions at $\mathrm{C} 1$, that is, shorter spring vegetative growth derived from delayed March warming and early (and longer) summer droughts (Fig. 2, Table A1).

Synchrony in acorn production in the $Q$. suber populations studied was very low on all sites (Table 3 , Fig. 4) but was greatly enhanced when trees were grouped by acorn production type. CVp also increased when grouping trees by acorn production type while mean CVi did not change (Table 3 ). ACF1i values were lower in A trees than in B trees (Table 3).

\section{Weather parameters as determinants of acorn production}

Q. suber acorn production was correlated with weather variables, but the explained variability was very low (7.6\%; Table 4a), making the interpretation difficult. The variance remained low even if the regressions were performed separately for each site (not shown). However, when disaggregating the trees by their acorn production pattern (A trees, B trees), the total variance explained increased sixfold and the weather variables were easier to interpret (Table 4b,c). In both A and B trees, acorn production was related mainly to precipitation, and secondarily to temperature. For A trees, production increased with June precipitation (explained var. 23.3\%) and April temperatures, and decreased with high June-July temperatures in the previous year, summer water deficit and number of frost days in March (Table 4b). For B trees, production increased mainly with September precipitation (i.e., during acorn ripening; explained var. $22.7 \%$ ) and number of frost days in March, and decreased with high June-July temperatures in the previous year, April temperatures and June precipitation (Table 4c). For the two models, for A trees and for B trees, the explained deviance was over $44 \%$ (Table 3 ).

\section{Discussion}

Acorn production variability in Cork oak was related to water availability, especially to summer drought. This result is in agreement with results obtained from other Mediterranean oaks (GarcíaMozo et al. 2007, Espelta et al. 2008, Carevic et al. 2010, Pérez-Ramos et al. 2010). Variability values were also within the range observed for other oaks (Koenig et al. 2003, Espelta et al. 2008), with mean individual (temporal) variability (CVi) higher than population (spatial) variability (CVp). Nevertheless, in Quercus suber, the effect of climate on acorn production was masked by the coexistence of acorns with different maturation patterns (annual and biennial acorns). When considering all trees or all the trees from a given geographical location, synchrony in acorn production was very low compared to other oaks (Table 3, Fig. 4), and all the regressions tested with weather parameters led to very low explained variance (Table 4a). However, both the temporal synchrony in acorn production and the explained variance of the weather regression increased drastically when the trees with annual acorns were disaggregated from those with biennial acorns (A and B trees, Table 4b, c, Fig. 4). In general, the most important factors for acorn production were water-related parameters (for other Mediterranean oaks see Espelta et al. 2008 and Pérez-Ramos et al. 2010): summer precipitation for annual trees or September precipitation (i.e., when acorns start to grow) for biennial trees. More specifically, trees with annual acorns responded to favourable conditions during leaf renewal and female fertilizations (high June precipitation; low water deficit) and to mild temperatures (low number of frost days in spring, elevated temperatures in April). In contrast, trees with biennial acorns responded positively to water availability at the end of summer and to spring frosts. Indeed, some variables showed an opposite effect on each group of trees (Table 4), suggesting an interaction effect between the two types of acorns. That is, conditions that negatively affect annual production could be beneficial for biennial production (and vice-versa). This interaction may suggest the existence of a trade-off at branch level, in a way similar to the 
trade-off between vegetative growth and acorn production described in other oaks (SánchezHumanes et al. 2011). For instance, late March frost shortens the time window for acorn maturation (García-Mozo et al. 2001) before summer drought, and thus decreases the annual acorn production. However, the incipient acorns may mature the following year, thus increasing biennial acorns. In fact, maximum acorn production would be expected in a year with good conditions for annual acorn production, preceded by a year that was inappropriate for annual production. A detailed monitoring of individual acorns would be needed for a deeper understanding of acorn dynamics and the processes behind acorn production variability in $Q$. suber.

All the populations studied had trees with annual acorns as well as trees with biennial acorns, although the proportions of each type were different. Annual acorn types were more frequent in E2 and P1 than on the other sites. These two sites were closer to the Mediterranean Sea and at lower altitudes (Table A1 in ESM), which implies more mesic conditions derived from warmer winters, higher precipitation, more frequent fogs (and thus enhanced summer water availability; Estrela et al. 2008) and shorter summer droughts. Thus, a biennial acorn production seems to be a response to harsher climatic conditions (Elena-Roselló et al. 1993), as in the case of our Calderona site.

Our classification of annual and biennial trees was indirect and made a posteriori because of the difficulties we encountered to differentiate annual and biennial acorns in the field. Nevertheless, we have confidence in this classification for several reasons: 1) the explained variance in the regressions with weather variables increased extraordinarily, and this cannot be expected by chance alone; 2) it is consistent with the expected differences in temporal autocorrelation in most of the oak species analysed (Koenig et al. 2003); and 3) it is supported by previous (although limited) observations of marked acorns in the study area (on the basis of 27 trees marked in 2003 at the three locations studied, 12 out of 15 trees in Calderona showed an annual/biennial acorn ratio $<0.25$, while 3 of 12 trees showed this value in Espadà and Pinet; unpublished data from the authors).

An open question is why trees with annual acorn production coexist with trees with biennial production. The microclimatic conditions of each tree (e.g., soil depth, slope, stoniness) may enhance or smooth stressful conditions and drive variations in acorn maturation. Other conditions like age, time since cork harvesting or the number of previous harvests may also contribute to shaping individual responses to climatic conditions. The ability to modulate the acorn production pattern of a given year according to the environmental conditions could be regarded as an example of phenotypic plasticity for facing variable and uncertain climatic conditions (Rehfeldt et al. 2001, Nocotra et al. 2010). This may not be exclusive of $Q$. suber; for example, $Q$. coccifera also shows a complex and diverse phenological pattern (Bianco and Schirone 1985). To what extent other oaks living in variable and stressful conditions behave similarly remains to be explored.

\section{Acknowledgements}

We thank Cristina Beseler and Aina Blasco for collaborating in the field sampling and Patricio García-Fayos for insights on an early version of manuscript. This work was funded by the European project CREOAK (QLRT-2001-01594) and the Spanish projects VARQUS (CGL200404325/BOS) and GRACCIE (Consolider-Ingenio2010). CEAM-UMH is supported by Generalitat Valenciana, Bancaixa, and the Spanish government (GRACCIE Consolider-Ingenio2010); CIDE is supported by Generalitat Valenciana, the Spanish National Research Council (CSIC) and the University of Valencia. The experiment complies with the current laws of Spain. 


\section{References}

Abrahamson WG, Layne JN (2003) Long-term patterns of acorn production for five oak species in xeric Florida uplands. Ecology 84:2476-2492

Aronson J, Pereira JS, Pausas JG (eds) (2009) Cork Oak Woodlands on the Edge: Ecology, Adaptive Management, and Restoration. Island Press, Washington, DC

Bianco P, Schirone B (1985) On Quercus coccifera L. s.l.: variation in reproductive phenology. Taxon 34:436-439

Bugalho MN, Caldeira MC, Pereira JS, Aronson J, Pausas JG (2011) Mediterranean cork oak savannas require human use to sustain biodiversity and ecosystem services. Frontiers in Ecology and the Environment 9:278-286

Buonaccorsi JP, Elkinton JS, Evans SR, Liebhold AM (2001) Measuring and testing for spatial synchrony. Ecology 82:1668-1679

Carevic FS et al. (2010) Plant water relations and edaphoclimatic conditions affecting acorn production in a holm oak (Quercus ilex L. ssp. ballota) open woodland. Agroforestry Systems 78:299-308

Cecich RA, Sullivan NH (1999) Influence of weather at time of pollination on acorn production of Quercus alba and Quercus velutina. Canadian Journal of Forest Research 29:1817-1823

Díaz-Fernández PM, Climent J, Gil L (2004) Biennial acorn maturation and its relationship with flowering phenology in Iberian populations of Quercus suber. Trees Structure and Function 18:615-621

Elena-Rosello R, de Rio JM, Garcia Valdecantos JL, Santamaría IG (1993) Ecological aspects of the floral phenology of the cork-oak (Q. suber L): why do annual and biennial biotypes appear? Annales des Sciences Forestieres 50:114s-121s

Ellison AM et al. (2005) Loss of foundation species: consequences for the structure and dynamics of forested ecosystems. Frontiers in Ecology and the Environment 3:479-486

Espelta JM, Cortés P, Molowny-Horas R, Sánchez-Humanes B, Retana J (2008) Masting mediated by summer drought reduces acorn predation in mediterranean oak forests. Ecology 89:805817

Estrela MJ, Valiente JA, Corell D, Millán MM (2008) Fog collection in the western Mediterranean basin (Valencia region, Spain). Atmospheric Research 87:324-337

Fearer TM, Norman GW, Pack JC, Bittner S, Healy WM (2008) Influence of physiographic and climatic factors on spatial patterns of acorn production in Maryland and Virginia, USA. Journal of Biogeography 35:2012-2025

García-Mozo H, Gómez-Casero MT, Domínguez E, Galán C (2007) Influence of pollen emission and weather-related factors on variations in holm-oak (Quercus ilex subsp. ballota) acorn production. Environmental and Experimental Botany 61:35-40

García-Mozo H, Hidalgo PJ, Galan C, Gómoz-Casero MT, Domínguz E (2001) Catkin frost damage in Mediterranean cork-oak (Quercus suber L.). Israel Journal of Plant Sciences 49:41-47

Hampe A, Petit R (2005) Conserving biodiversity under climate change: the rear edge matters. Ecology Letters 8:461-467

Kelly D, Sork VL (2002) Mast Seeding in Perennial Plants: Why, How, Where? Annual Review on Ecology \& Systematics 33:427-447

Koenig WD, Carmen WJ, Stanback MT, Mumme RL (1991) Determinants of acorn productivity among five species of oaks in central coastal California. In: Standiford RB (ed) Proceedings of the symposium on oak woodlands and hardwood rangeland management. Gen. Tech. Rep. PSW-GTR-126. Berkeley, CA: Pacific Southwest Research Station, Forest Service, U.S. Department of Agriculture, pp 136--142 
Koenig WD et al. (2003) Dissecting components of population-level variation in seed production and the evolution of masting behavior. Oikos 102:581-591

Koenig WD, Knops JMH (2000) Patterns of annual seed production by northern hemisphere trees: A global perspective. American Naturalist 155:59-69

LaMontagne JM, Boutin S (2007) Local-scale synchrony and variability in mast seed production patterns of Picea glauca. Journal of Ecology 95:991-1000

LaMontagne JM, Boutin S (2009) Quantitative methods for defining mast-seeding years across species and studies. Journal of Vegetation Science 20:745-753

Lesica P, Allendorf FW (1995) When are peripheral populations valuable for conservation? Conservation Biology 9:753-760

Logan WB (2005) Oak: the frame of civilization. WW Norton \& Company

Magri D et al. (2007) The distribution of Quercus suber chloroplast haplotypes matches the palaeogeographical history of the western Mediterranean. Molecular Ecology 16:5259-5266

McShea WJ, Healy WM (eds) (2002) Oak Forest Ecosystems: ecology and management for wildlife. John Hopkins University Press

Millán MM, Estrela MJ, Miró J (2005) Rainfall components: Variability and spatial distribution in a Mediterranean area (Valencia region). Journal of Climate 18:2682-2705

Montero G, Cañellas I (2003) Selvicultura de los Alcornocales en España. Silva Lusitana 11:1-19

Nicotra AB et al. (2010) Plant phenotypic plasticity in a changing climate. Trends in Plant Science 15:684-692

Ostfeld RS, Jones CG, Wolff JO (1996) Of mice and mast: ecological connections in eastern deciduous forests. BioScience 46:323-330

Pausas JG (1997) Resprouting of Quercus suber in NE Spain after fire. Journal of Vegetation Science 8:703-706

Pausas JG, Pereira JS, Aronson J (2009) The tree. In: Aronson J, Pereira JS, Pausas JG (eds) Cork Oak Woodlands on the Edge: conservation, adaptive management, and restoration. Island Press, Washington, DC, pp 11-21

Pausas JG, Ribeiro E, Dias SG, Pons J, Beseler C (2006) Regeneration of a marginal Quercus suber forest in the eastern Iberian Peninsula. Journal of Vegetation Science 17:729-738

Pérez Cueva AJ (1994) Atlas climàtic de la Comunitat Valenciana (1961-1990). Generalitat Valenciana, Valencia

Pérez-Ramos IM, Ourcival JM, Limousin JM, Rambal S (2010) Mast seeding under increasing drought: results from a long-term data set and from a rainfall exclusion experiment. Ecology 91:3057-3068

Pons J, Pausas JG (2006) Oak regeneration in heterogeneous landscapes: The case of fragmented Quercus suber forests in the eastern Iberian Peninsula. Forest Ecology and Management 231:196-204

Pons J, Pausas JG (2008) Modelling jay (Garrulus glandarius) abundance and distribution for oak regeneration assessment in Mediterranean landscapes. Forest Ecology and Management 256:578-584

Rehfeldt GE, Wykoff WR, Ying CC (2001) Physiologic plasticity, evolution, and impacts of a changing climate on Pinus contorta. Climatic Change 50:355-376

Rodà F, Retana J, Gracia CA, Bellot J (eds) (1999) Ecology of Mediterranean Evergreen Oak Forests. Springer, Berlin

Rubio JL, Sánchez J, Forteza J (1995) Mapa de suelos de la Comunidad Valenciana, Sagunto (668). Proyecto LUCDEME, Generalitat Valenciana

Sánchez-Humanes B, Sork V, Espelta J (2011) Trade-offs between vegetative growth and acorn production in Quercus lobata during a mast year: the relevance of crop size and hierarchical level within the canopy. Oecologia 166:101-110 
Schmidt KA, Ostfeld RS (2003) Songbird populations in fluctuating environments: predator responses to pulsed resources. Ecology 84:406-415

Serrasolses I et al. (2009) Soil properties constraining cork oak distribution. In: Aronson J, Pereira JS, Pausas JG (eds) Cork Oak Woodlands on the Edge: conservation, adaptive management, and restoration. Island Press, Washington, DC, pp 89-99

Thornthwaite CW, Mather JR (1957) Instructions and tables for computer potential evapotranspiration and water balance. Publ.Clim. 10(3).

Venable DL, Brown JS (1988) The selective interactions of dispersal, dormancy, and seed size as adaptations for reducing risk in variable environments. The American Naturalist 131360 362

Wolff JO (1996) Population fluctuations of mast-eating rodents are correlated with production of acorns. Journal of Mammalogy 77:850-856 


\section{Tables}

Table 1. List of weather parameters considered in this study and their biological relevance.

\begin{tabular}{|c|c|c|c|}
\hline Code & Description & Relevance & Ref \\
\hline $\mathrm{P}$ & Annual precipitation (mm) & General resource availability & 2 \\
\hline $\begin{array}{l}\text { Psp, Psu, } \\
\text { Pau, Pwi }\end{array}$ & $\begin{array}{l}\text { Spring, Summer, Autumn and Winter } \\
\text { precipitation }(\mathrm{mm})\end{array}$ & $\begin{array}{l}\text { Seasonal resource } \\
\text { availability }\end{array}$ & 2,7 \\
\hline P6 & June precipitation (mm) & Female flower maturation & 1 \\
\hline P9 & $\begin{array}{l}\text { September Precipitation (just before acorn } \\
\text { crop) }(\mathrm{mm})\end{array}$ & Acorn maturation & 4,6 \\
\hline T4, T5 & Mean temperature in April, and in May $\left({ }^{\circ} \mathrm{C}\right)$ & Male flowers & 1,2 \\
\hline T67 & Mean June-July temperature & Female flowers & 1 \\
\hline WD, DI & $\begin{array}{l}\text { Annual water deficit (mm, mainly summer } \\
\text { drought) and Drought Index }\end{array}$ & Acorn abortion & $2,7,5$ \\
\hline FD3b & $\begin{array}{l}\text { Number of frost days in the second half of } \\
\text { March }\end{array}$ & Catkin frost & 3 \\
\hline FDsp & Spring frost days (March-April) & Catkin frost & 3 \\
\hline
\end{tabular}

References: 1) Elena-Rosello et al. 1993; 2) Koenig et al. 1996; 3) Garcia-Mozo et al. 2001: 4) Garcia-Mozo et al. 2007: 5) Espelta et al. 2008; 6) Montserrat-Martí et al. 2009; 7) Ramos et al. 2010

Table 2. Number of trees masting in 2008 (A trees) and in 2009 (B trees), and those with no clear masting pattern ( $\mathrm{C}$ trees), on the five sites studied. In brackets are the proportion of each production group over total trees on each site. Espadà: E1, E2; Calderona: C1,C2; Pinet: P1. (see text for details).

\begin{tabular}{lcccccc}
\hline & E1 & E2 & C1 & \multicolumn{1}{c}{ C2 } & P1 & Total \\
\hline A trees & $11(44.0)$ & $25(73.5)$ & $3(6.7)$ & $6(26.1)$ & $14(50.0)$ & $59(38.1$ \\
B trees & $3(12.0)$ & $5(14.7)$ & $19(42.2)$ & $12(52.2)$ & $1(3.6)$ & $40(25.8)$ \\
C trees & $11(44.0)$ & $4(11.8)$ & $23(51.1)$ & $5(21.7)$ & $13(46.4)$ & $56(36.1)$ \\
Total & 25 & 34 & 45 & 23 & 28 & 155 \\
A/B ratio & 3.7 & 5.0 & 0.2 & 0.5 & 14.0 & 1.5 \\
\hline
\end{tabular}


Table 3. Variability parameters of acorn production for the different populations studied: population variability $(\mathrm{CVp})$, individual variability $(\mathrm{CVi})$, mean individual synchrony $(\mathrm{Rp})$ and mean temporal autocorrelation (ACF1i).

\begin{tabular}{lccccc}
\hline Population & $\mathrm{n}$ & CVp & CVi & $\mathrm{Rp}$ & ACF1i \\
\hline & & & & & \\
E1 & 24 & 95.5 & 183.5 & 0.245 & -0.100 \\
E2 & 33 & 113.6 & 183.4 & 0.484 & -0.197 \\
C1 & 44 & 106.7 & 182.1 & 0.248 & -0.061 \\
C2 & 23 & 108.0 & 187.1 & 0.344 & -0.129 \\
P1 & 28 & 64.3 & 143.5 & 0.333 & -0.260 \\
Overall & 155 & 67.9 & 176.4 & 0.193 & -0.143 \\
& & & & & \\
A trees & 59 & 139.8 & 174.7 & 0.772 & -0.256 \\
B trees & 40 & 175.4 & 186.8 & 0.730 & -0.081 \\
C trees & 53 & 86.0 & 170.6 & 0.268 & -0.068
\end{tabular}


Table 4. Summary of the stepwise selection for the regressions of the standardized acorn production against weather variables, for all trees, A (presumably annual) and B (presumably biennial) trees. Columns are the Akaike Information Criteria (AIC), the log-likelihood, the likelihood ration test (LR; with a change of 1 degree of freedom) and the associated $p$-value for the mixed-effects model. The Null model refers to the model with only random effects, and no fixed effects. The last column (Coef) refers to the coefficients of the final model (all coefficients are significant at $p<0.05$ ). The explained deviance of each model is: 7.57\% (all trees), 44.14 (A trees), and $44.58 \mathrm{~B}$ trees).

\begin{tabular}{lccccc}
\hline & AIC & $\operatorname{logLik}$ & LR & p-value & Coef. \\
\hline $\begin{array}{l}\text { a) All trees } \\
\text { Null }\end{array}$ & 3324.37 & -1658.19 & & & \\
+ T67(-1) & 3221.68 & -1605.84 & 104.70 & $<0.0001$ & -0.302 \\
+ WD & 3106.94 & -1547.47 & 116.73 & $<0.0001$ & -0.004 \\
+ FD3b & 3083.89 & -1534.94 & 25.06 & $<0.0001$ & -0.265 \\
+ T4 & 3081.35 & -1532.68 & 4.54 & 0.0332 & 0.060
\end{tabular}

b) A trees

+ P6

$1270.21 \quad-631.11$

$+\mathrm{T} 4$

$978.47 \quad-484.24$

$892.90 \quad-440.45$

293.74

$<0.0001$

0.007

$87.58<0.0001 \quad 0.316$

+ T67(-1)

$821.99-403.99$

72.91

$<0.0001$

$-0.245$

$746.74 \quad-365.37$

77.25

$<0.0001 \quad-0.007$

+ FD3b

$723.12 \quad-352.56$

$25.62<0.0001$

$-0.338$

c) B trees

$\begin{array}{llllll}\text { Null } & 867.70 & -429.85 & & & \\ + \text { P9 } & 674.35 & -332.17 & 195.35 & <0.0001 & 0.007 \\ + \text { T67(-1) } & 562.58 & -275.29 & 113.76 & <0.0001 & -0.365 \\ \text { + FD3b } & 512.92 & -249.46 & 51.66 & <0.0001 & 0.731 \\ \text { + T4 } & 501.07 & -242.54 & 13.85 & 0.0002 & -0.145 \\ \text { + P6 } & 494.43 & -238.21 & 8.64 & 0.0033 & -0.005\end{array}$


Figures

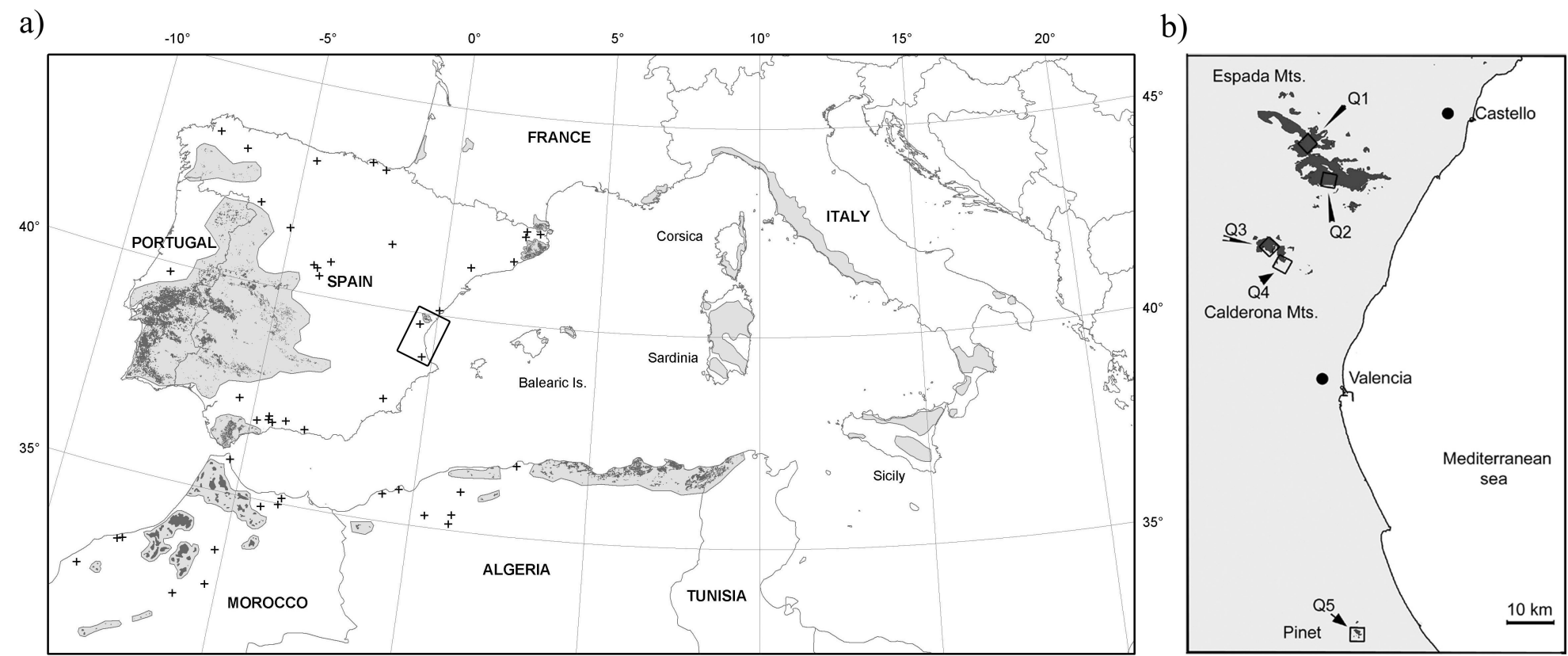

Figure 1. (a) Distribution of Cork oak (Quercus suber) (grey area and crosses; from Pausas et al. 2009, with permission from Island Press) indicating the location of the study area in the eastern Iberian Peninsula (squared); and (b) location of the five sampled sites: from north (top) to south (bottom), two sites in the Espadà mountains (E1, E2), two in the Calderona mountains (C1, C2) and one site in Pinet (P1); dark gray indicates $Q$. suber distribution (own data) 


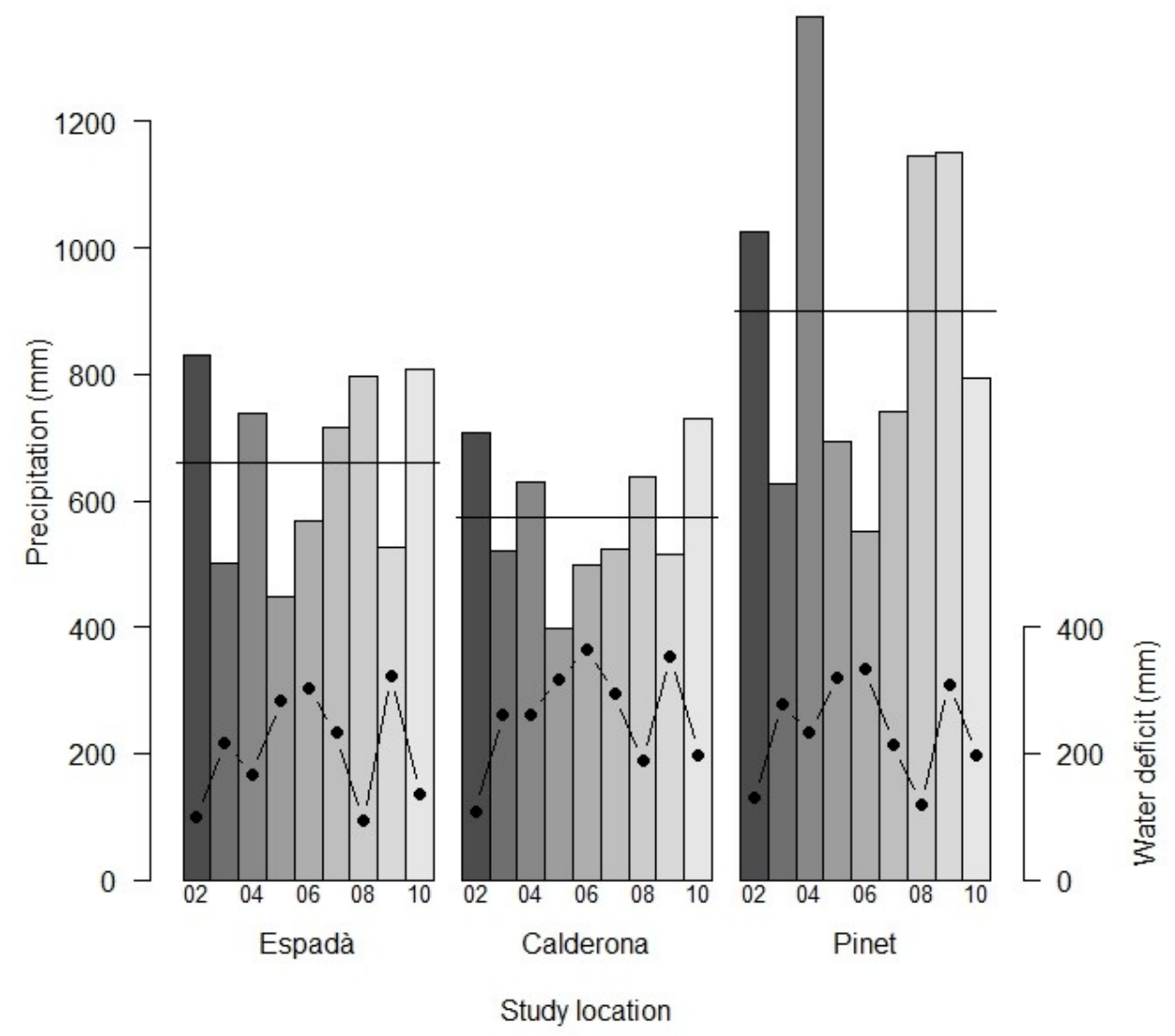

Figure 2. Precipitation (bars) and water deficit (dots and lines) at the three sampling locations (including 2002, the year previous to the start of the study). Data are for hydrological year

(September to August). Horizontal lines indicate the mean precipitation value for each site. Monthly climatic variability is shown in Fig. A1 of the ESM 

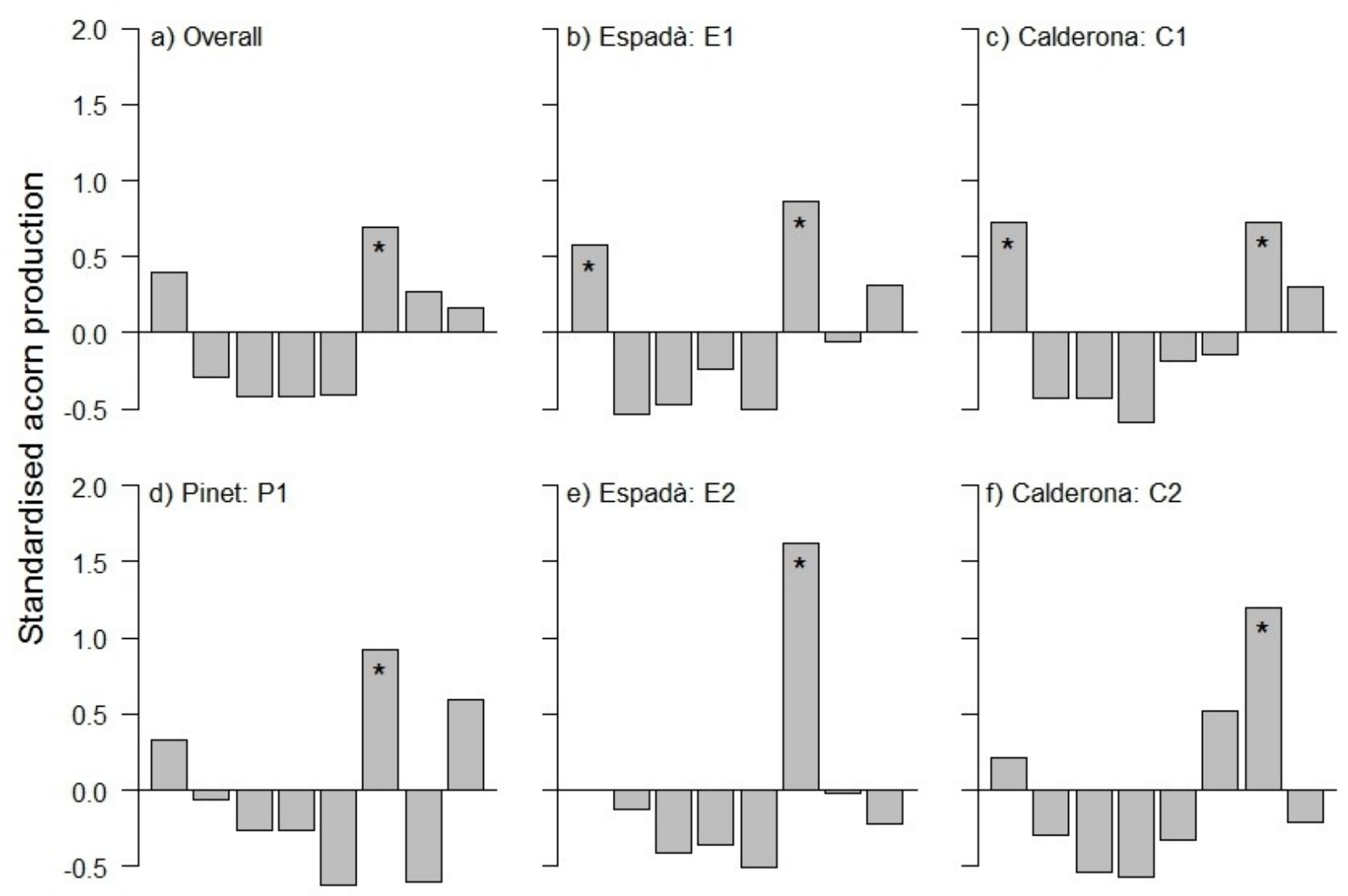

$03 \quad 05 \quad 07 \quad 09$
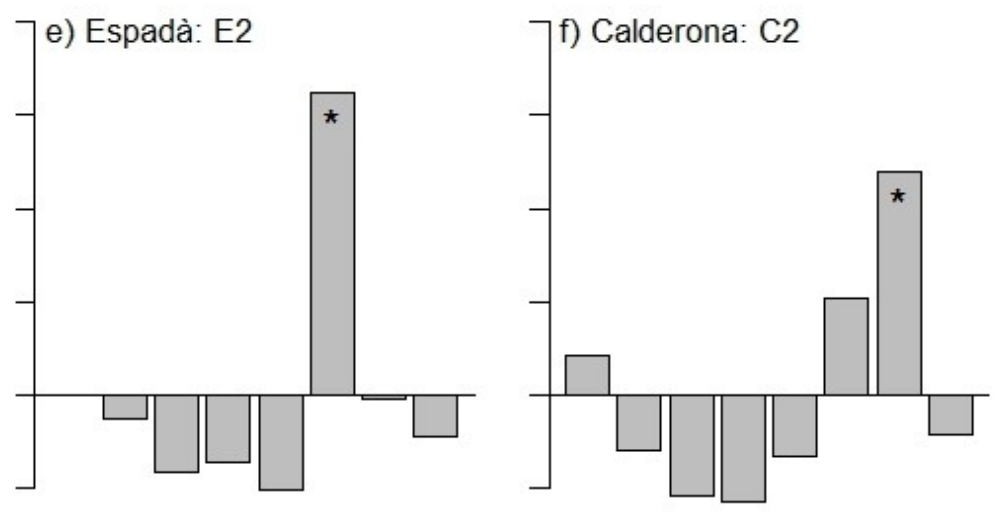

$\begin{array}{cccc}03 & 05 & 07 & 09 \\ \text { Year } & \end{array}$

$03 \quad 05 \quad 07 \quad 09$

Figure 3. a) Standardised acorn production for all trees (overall), and for each site b)-f). Years with an asterisk $\left(^{*}\right)$ are mast years, which the annual standardized deviation of acorn production was greater than the absolute magnitude of the variation below the mean (Lamontagne and Boutin 2007). Data for individual trees is shown in Fig. A3 of the ESM 


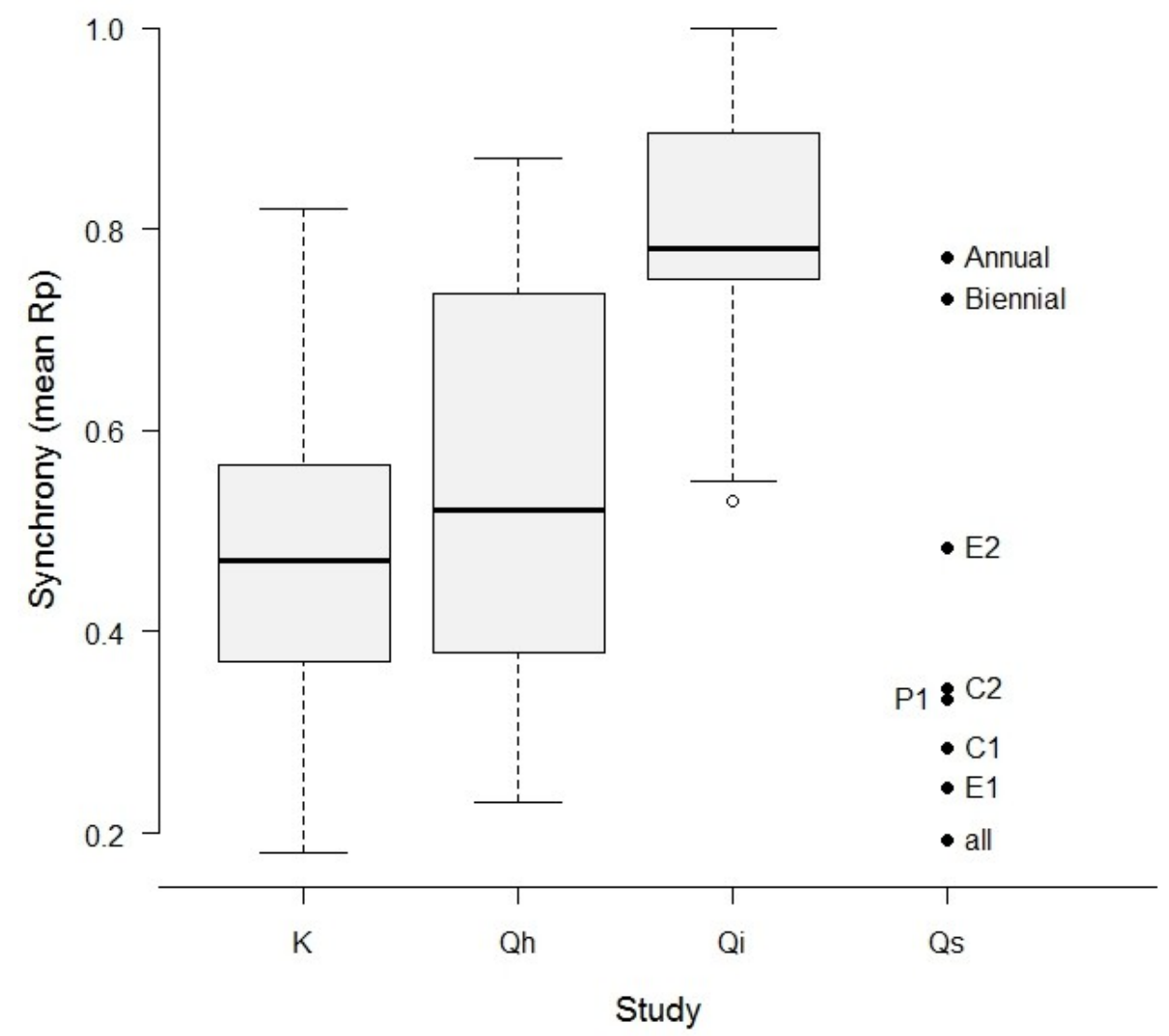

Figure 4. Synchrony values for different Quercus species. K: North American oaks (Koenig et al. 2003); Qh and Qi: Quercus humilis and Q. ilex (Espelta et al. 2008); Qs: data from the Quercus suber locations in this study, including the aggregation of trees by annual and biennial acorn production pattern ( $\mathrm{A}$ and $\mathrm{B}$ trees). In all cases synchrony is expressed as a mean of the pairwise Pearson correlation between all individuals. Variability in K, Qs, and Qi refers to different sites 